I wish to make grateful acknowledgement to $\mathrm{Mr}$ J. Taylor of East Malling Research Station for his assistance with the statistical analysis involved in this paper. $\mathbf{M r}$ W. Arthington assisted in carrying out the experimental work. The work described in this paper was carried out as part of the programme of the Food Investigation Board of the Department of Scientific and Industrial Research.

\title{
REFERENCES
}

Fisher, R. A. (1928). Statistical Methods for Research Workers, 2nd ed., p. 44 et seq. London: Oliver and Boyd: Hulme, A. C. (1936a). Biochem. J. 30, 258.

Hulme, A. C. (1936b). Rep. Food Invest. Bd, Lond., p. 128.

Hulme, A. C. (1937). Rep. Food Invest. Bd, Lond., p. 133.
Hulme, A. C. \& Roach, W. A. (1936). Biochem. J. 30, 1397.

Hulme, A. C. \& Smith, W. H. (1938). Rep. Food Invest. $B d$, Lond., p. 127.

Kidd, F. \& West, C. (1932). Rep. Food Invest. Bd, Lond., p. 55 .

\section{The Algae}

\section{THE LIPOCHROMES OF THE MALE AND FEMALE GAMETES OF SOME SPECIES OF THE FUCACEAE}

\author{
By P. W. CARTER, L. C. CROSS, I. M. HEILBRON AND E. R. H. JONES \\ Organic Chemistry Department, Imperial College of Science and Technology, London, \\ and Botany Department, University College of Wales, Aberystwyth
}

\section{(Received 9 February 1948)}

Biochemical work done hitherto on the algae has been concerned chiefly with the vegetative thallus. Mainly because of the difficulties of securing pure material in sufficiently large quantities, very little consideration has until recently been given to the pigmentation of the reproductive bodies. Among the lower plants, the male gametes of many algae are known to be yellowish in colour, in contrast to the rather more green female gametes, and this difference is especially marked in heterogamous and oogamous plants.

The members of the family Fucacere (class Phaeophyceas), so abundant on many parts of our British shores, reproduce oogamously by means of minute motile, biciliate sperms and larger nonmotile eggs. The dioecious members of the Fucales are especially convenient for study, in that large quantities of both male and female gametes can be obtained in a pure state and free from any possibility of contamination by gametes of the other sex. In the same family, monoecious species also occur, and thus provide material for comparison with the dioecious types.

In the Fucaceae, the antheridia and oogonia are produced within flask-shaped, sunken cavities, the conceptacles. These occur at the periphery of somewhat swollen and mucilaginous receptacles, which in some species are modifications of some of the dichatomies of the thallus as in Fucus serratus, $F$. vesiculosus and $F$. spiralis, or in other genera, of the apices of special lateral deciduous fruiting bodies, as in Ascophyllum nodosum.
The gradual extrusion of groups of mature eggs and sperms through the openings (ostioles) of the concepteicles, normally occurs between the tides, and is probably brought about in part by the expansion of mucilage, together with contraction on desiccation. In nature, the gametes are removed from the surface of the conceptacles by the incoming tide and fertilization thus takes place outside the parent plant.

The numerous minute biciliated sperms contain a small yellowish chromoplast, and the mature aggregates of sperms therefore appear orange-yellow, which colour they impart to the entire receptacle. This affords a means of distinguishing the male plants in the dioecious species of the Fuci at the time of gamete discharge. In the preparation of material for the present experiments, however, colour alone was not considered to be a sufficiently safe criterion, and a section of a receptacle of every plant collected was examined microscopically, in order to confirm the accuracy of the separation of the male and female plants. Moreover, plants were selected from all parts of the zone of their distribution on the Aberystwyth shore.

The marked orange colour of the exudate of the male plants of the dioecious members of the Fucacese in their fruiting season, in striking contrast to the olive-green colour of the female-plant exudate, suggested that the colouring matter of the chromatophores of the male and female gametes might possibly be connected with the reproductive process. It seemed feasible that the light-absorbing 
properties of the pigments might be responsible for the motility of the male gametes prior to fertilization of the female egg (oosphere).

Immersion in water of the receptacles of the fruiting male plants collected at low tide produces a bright orange suspension of sperms and antheridia, whilst from the fruiting female plants a suspension of eggs (and oogonia) and copious mucilage is secured. From the fruiting monoecious plants, a mixture of eggs and sperms is obtained, the proportions of each varying somewhat during the fruiting period. In the earlier experiments on Fucus serratus the orange exudate was removed by wiping, but this method was later rejected in favour of dipping the receptacles in water. From these suspensions the pigments can be extracted with ether or light petroleum, or better still the suspension can be concentrated by centrifuging or filtration. The suspension obtained in sea water consists almost exclusively of active freeswimming sperms with empty antheridial vesicles from which the sperms have been released. A suspension in fresh or distilled water, on the other hand, consists mainly of antheridia with undischarged gametes which renders the process of concentration easier. From the male exudate an orange solution is thus obtained, containing a pigment which exhibits the normal properties of a carotenoid hydrocarbon or ester, i.e. solubility relationships, absorption spectrum, coloration with antimony trichloride in chloroform solution and adsorption properties on alumina, calcium hydroxide and magnesium oxide.

It has been established that the characteristic carotenoid pigments of fresh brown algae are $\beta$ carotene and fucoxanthin (Heilbron, Parry \& Phipers, 1935; Carter, Heilbron \& Lythgoe, 1939; Heilbron, 1942), while in algae which have been kept in a dry condition the latter pigment is replaced by zeaxanthin (Heilbron \& Phipers, 1935). A detailed examination of the pigments of the male exudate of the dioecious brown algae Ascophyllum nodosum Le Jol, Fucus serratus Linn. and F. vesiculosus Linn., has revealed that the predominating orange pigment, unaffected by alkaline hydrolysis, is the hydrocarbon $\beta$-carotene, already known to be the typical epiphasic carotenoid of the brown algae. A number of other carotenoid pigments is certainly present in very minute quantities; some of these may be isomeric forms of carotene (Carter \& Gillam, 1939; Zechmeister, 1944), but although considerable amounts of algae have been employed (the exudate from $250 \mathrm{~kg}$. of Ascophyllum nodosum was extracted) it has not been possible to isolate any other pigment in sufficient quantity even for spectrographic analysis. It is of interest to note that, among the fungi, the small motile male gamete of some species of Allomyces (e.g. A. javanicus) is known to possess a conspicuous orange globule, whilst the larger female gametes are colourless. Emerson \& Fox
(1940) have found that this orange colour is due to carotenoid pigments, in particular to $\gamma$-carotene along with traces of isomers. Also the thick-walled sporangia produced during the sporophytic phase in the life cycle of this fungus contain a brown pigment of the melanin group and no trace of carotenoids.

In direct contrast to the results obtained with the male exudates our examination of the pigments of the corresponding female exudates indicated that chlorophyll and fucoxanthin, both typical pigments of the brown algae, are almost entirely responsible for the colour of the female gametes. Only traces of $\beta$-carotene were detected in the extracts, but the fact that the egg possesses a representative sample of the pigments of the parent plant, even in differing proportions, is not unexpected. The crude concentrated extracts of both male and female gametes were largely contaminated with oily impurities, presumably terpenoid in nature, in which the carotenoids are dissolved in the cell chromatophores. (Such materials have been shown (Haas \& Hill, 1933) to be present in many members of the Phaeophyceae, and to be more abundant in species growing high in the littoral zone.) These contaminants, particularly in the case of the male exudate, were undoubtedly responsible for the poor yields of $\beta$-carotene obtained in a crystalline form, since chromatographic adsorption failed to separate the pigment from these oily impurities. The quantity of fucoxanthin in the female exudate was considerably less than that of the $\beta$-carotene in the male; so small was the amount of the former that only from Ascophyllum nodosum could any solid material be obtained.

Resolution of the exudate pigments of the monoecious species Fucus spiralis Linn., gave results similar to those of the dioecious members examined, in that $\beta$-carotene, fucoxanthin and chlorophyll were all present in the mixed exudate, the carotene presumably arising from the orange sperms and the two latter pigments from the greenish eggs.

\section{EXPERIMENTAL}

All melting points are uncorrected. The light petroleum used in these experiments had b.p. range 40-60 . Anhydrous $\mathrm{Na}_{2} \mathrm{SO}_{4}$ was employed for drying solutions, and all operations were carried out under $\mathrm{N}_{2}$, evaporations being effected under reduced pressure. Alumina refers to Brockmann's 'special for adsorption'; MgO was always diluted with an equal bulk of Hyflo Super-Cel (Strain, 1934). $\mathrm{Ca}(\mathrm{OH})_{2}$ was activated before use by heating at $130^{\circ}$ for $1 \mathrm{hr}$. Elutions were effected with a $5 \%$ solution of methanol in light petroleum except where otherwise stated.

Fucus vesiculosus, male. A concentrate of sperms from $13 \mathrm{~kg}$. of the whole fruiting alga was obtained by allowing the alga to stand for 12-24 hr. in a moist atmosphere, and then washing off the exuded material by dipping into a small volume of water. This treatment of the fruiting plants is reasonably comparable with the intertidal conditions on the shore, when the expulsion of the repro- 
ductive bodies from the conceptacles is known to take place. The concentrate was centrifuged to remove as much water and mucilage as possible, and the orange residue then ground with anhydrous $\mathrm{Na}_{2} \mathrm{SO}_{4}$. Treatment of the moist cake so obtained first with methanol and then with light petroleum gave a solution which contained almost all the pigments of the original exudate. The petroleum-methanol solution was washed with water; the resulting light petroleum solution* was then shaken with an equal volume of $95 \%$ methanol, but no hypophasic pigments could be separated. The washed and dried light petroleum solution was adsorbed on a column of calcium hydroxide, the chromatogram being developed with the same solvent. The final chromatogram was essentially similar to those obtained from the exudates from male Ascophyllum nodosum and Fucus serratus (see later), consisting of a lower orange carotene zone in preponderating amount and a complex series of narrow bands in the upper portion of the column. The lower zone was eluted, and, after washing, the solvent was removed. Crystallization of the red oily residue yielded carotene $(9 \mathrm{mg}$.), which on recrystallization gave crystals of impure $\beta$-carotene (7 mg.); absorption maxima in carbon disulphide 517,484 and $454 \mathrm{~m} \mu$.

Ascophyllum nodosum, male. The suspension of sperms and antheridia from some $250 \mathrm{~kg}$. of the fruiting alga was treated by a technique similar to that described under Fucus vesiculosus, male, except that the suspension was filtered through coarse fluted filter papers which were then extracted with acetone-light petroleum (1:4).

By elution of the carotene zone of the chromatogram and crystallization of the resultant red oil (140 mg.) from benzene-methanol, $\beta$-carotene (16 mg., m.p. 178 $)$ was obtained as red leaflets with a greenish metallic lustre; absorption maxima in carbon disulphide 517, 487 and $455 \mathrm{~m} \mu$. (Carter et al. 1939).

Traces of fucoxanthin and chlorophyll, insufficient for characterization except by their behaviour on a chromatogram, were found in the hypophase.

Fucus serratus, male. The exudate was removed from the apices (5 kg.) by wiping with 'Kleenex' cellulose tissues, which were subsequently extracted with light petroleum, into which solvent the entire pigment was transferred.

Treatment of this solution by the technique already described gave a red oil (150 mg.), which on crystallization yielded $\beta$-carotene (3 mg.), m.p. 172 ${ }^{\circ}$. Absorption maxima in light petroleum 479-80 and $449 \mathrm{~m} \mu$.; in carbon disulphide 516 and 484-5 $\mathrm{m} \mu$.

The mother liquors obtained after separation of the crude carotene still contained much pigment, which was largely contaminated with oily impurities. In spite of saponification and several readsorptions this material failed to yield any further quantity of crystalline product.

Fucus vesiculosus, female. The exudate from $8 \mathrm{~kg}$. of fresh fruiting alga was treated by the technique developed with male $F$. vesiculosus, with the exception that the $\mathrm{Na}_{2} \mathrm{SO}_{4}$ cake was extracted first with acetone and then with ether. The combined extracts were washed, the dried solution was evaporated and the residue adsorbed, from

* This solution, and light petroleum solutions containing $\beta$-carotene from the other algae, before crystallization, exhibited absorption maxima at 477 and $447 \mathrm{~m} \mu$. while similar solutions in light petroleum (b.p. 60-80 ) showed maxima at 480 and $448 \mathrm{~m} \mu$. (cf. Carter \& Gillam, 1939). benzene solution, on a column of alumina, the chromatogram being developed with benzene. A pale-yellow filtrate passed through the colvmn, this consisting of a trace of $\beta$-carotene, which in light petroleum solution exhibited absorption maxima at 477 and $446 \mathrm{~m} \mu$. The only pigments adsorbed on the alumina were fucoxanthin and chlorophyll. The reddish brown zone of the former, occurring between two greenish bands, gave on elution the characteristic fucoxanthin blue coloration with $\mathrm{HCl}$. Absorption maxima in carbon disulphide were seen at 506-7, 477 and $446 \mathrm{~m} \mu$. A mixed chromatogram with pure fucoxanthin on alumina gave only one zone on development.

Ascophyllum nodosum, female. A concentrate of the exudate from $250 \mathrm{~kg}$. of the fresh fruiting alga was treated in a similar manner to that described for Fucus vesiculosus, female, except that the residue obtained after centrifuging was extracted directly and not treated with $\mathrm{Na}_{2} \mathrm{SO}_{4}$.

A trace of $\beta$-carotene was obtained as the epiphasic pigment, while the hypophase yielded chlorophyll and impure fucoxanthin (5.5 mg.). This pigment exhibited the characteristic fucoxanthin coloration on treatment in ether with $2.5 \mathrm{~N}-\mathrm{HCl}$. Absorption maxima in carbon disulphide occurred at 509, 478 and $453 \mathrm{~m} \mu$. (510, 477 and $455 \mathrm{~m} \mu$. given by Heilbron \& Phipers, 1935).

Fucus serratus, female. The exudate of the sexually active apices (4.5 kg.) was extracted in a manner similar to that described for $F$. serratus, male. No pigment could be extracted from the cellulose tissues with light petroleum, but extraction with ethanol gave a dark-green solution.

A trace of an epiphasic pigment, probably carotene, was present, whilst the main pigments, obtained in the hypophasic fraction, were chlorophyll and fucoxanthin. The latter was largely freed from chlorophyll by chromatography, and the pigment characterized by the blue coloration with HCl. Absorption maxima in carbon disulphide occurred at 508 and $473 \mathrm{~m} \mu$. with one at $670 \mathrm{~m} \mu$. due to presence of a little chlorophyll.

Fucus spiralis, male and female. A concentrate of the exudate from $18 \mathrm{~kg}$. of the fresh, sexually active alga was obtained and treated as described under $F$. vesiculosus, male. The $\mathrm{Na}_{2} \mathrm{SO}_{4}$ cake was extracted first with acetone and then with ether, the combined extracts were washed, dried and evaporated and the residue was partitioned between equal volumes of light petroleum and $95 \%$ methanol. The dark-green petroleum phase was washed with $95 \%$ methanol, then with water and dried, and the concentrated solution adsorbed on a column of $\mathrm{Ca}(\mathrm{OH})_{2}$, the chromatogram being developed with light petroleum. The chromatogram consisted of three uppermost greenish brown zones, then a series of very small bands, while the lower part, containing most of the carotenoid pigment, consisted of a single orange zone of $\beta$-carotene. Elution yielded insufficient material for crystallization, but the lightpetroleum solution showed absorption maxima at 477 and $447 \mathrm{~m} \mu$. (see footnote in previous column). The methanol hypophase was diluted with water and extracted with ether, the ethereal solution was washed, dried and evaporated, and the residue transferred to a small volume of dry benzene. This latter solution was adsorbed on a column of $\mathrm{Ca}(\mathrm{OH})_{2}$ and the chromatogram developed first with benzene and then with ether-benzene (1:4). The fucoxanthin formed an orange zone below the greenish zones, and on elution it gave the blue coloration with $\mathrm{HCl}$. Absorption maxima in carbon disulphide 476 and 446-7 $\mathrm{m} \mu$. 


\section{DISCUSSION}

The pigmentation of the respective gametes of the various Fuci examined is remarkably uniform. This result is not unexpected since the pigments and sterols of the whole plants of the order are similarly uniform (Carter et al. 1939). However, the prepon. derance of $\beta$-carotene in the sperm is unusual enough to promote speculation as to the function of that pigment.

In the Fuci, the sexual reproductive phase occurs at a particular period of the year extending in some species over several months, and in this respect the annual fruiting period is believed to spread over a longer period than in most other algae. The reproductive phase is usually followed by a period of vigorous vegetative growth, but elongation does not occur to any perceptible extent while the reproductive organs are being produced. On their discharge into sea water the sperms are extremely active and motile. The period of activity of the sperms, however, begins within the antheridial walls before final release through the apical pore of the antheridium. It might be expected that the energy expended by the sperm is obtained entirely, or in part, from light energy absorbed by the $\beta$-carotene which it contains, but evidence from some preliminary experiments which have been carried out suggests that the light absorbed by the $\beta$-carotene of the sperms after discharge has no connexion with the ciliary movements or with the fertilization process itself.

These experiments on the motility of Fucus sperms, using light of various wave lengths, suggest that the nature of the illumination affects activity only in so far as the velocity of movement and the length of the period of motility are concerned. There is evidence that the sperm suspension retains its vitality and fertilizing power for a relatively longer period if the activity is lessened, and loses it rapidly if the movement is violent. It seems, therefore, that the sperm is fully equipped with a store of energy at the time of discharge and its capacity for movement is determined by its activity and the rate of utilization of this energy store. This is in agreement with experiments on animal sperm activity, since
Cohn (1918) showed that the total carbon dioxide production of animal spermatozoa is the same whether their life be long or short.

The accumulation of carotenoid pigments in the reproductive phase and sexual organs is not unusual, and Murneek (1934) has demonstrated that the concentration of carotenoids reaches a maximum in the leaves of Cosmos, Salvia and Soja at about the time of flowering, after which there is a decrease. He points out a suggestive analogy with animals in which carotenoids are present in various organs and secretions usually associated with reproduction and in which the yellow pigments pass from other parts of the body to the reproductive organs, e.g. poultry and cattle.

Different proportions of pigments are reported in some male and female plants, and it appears (Murneek, 1934) that more yellow pigments are present in the female than the male of certain dioecious flowering plants (Rhamnus) and fungi (Mucor), whilst Delano \& Dick (1937) maintain that for some dioecious plants (willow and white poplar) there is more carotene and chlorophyll in the leaves of the male plant than in the female.

The physiological significance of carotenoid pigments in the plant is far from being understood, but within recent years a most important function of these pigments has been revealed. Picrocrocin, crocin and cis-trans-crocetin dimethyl esters have been demonstrated to play a fundamental role both in the copulation of the male and female gametes and in the subsequent sex determination in Chlamy. domonas eugametos (Kuhn, Moewus \& Jerchel, 1938; Kuhn, Moewus \& Wendt, 1939; Moewus, 1938).

\section{SUMMARY}

The predominating colouring matter of the male gametes of various brown algae has been shown to be $\beta$-carotene; fucoxanthin and chlorophyll are the pigments of the female gametes.

We are indebted to the Rockefeller Foundation for a grant in aid of this research. We wish to acknowledge the assistance given by the late Dr C. G. Eliot in the examination of Fucus serratus, female, and by Dr H. M. David in the laborious task of collecting material for this investigation.

\section{REFERENCES}

Carter, P. W. \& Gillam, A. E. (1939). Biochem. J. 33, 1325.

Carter, P. W., Heilbron, I. M. \& Lythgoe, B. (1939). Proc. Roy. Soc. B, 128, 82.

Cohn, E. J. (1918). Biol. Bull. Woods Hole, 34, 167.

Delano, N. \& Dick, J. (1937). Biochem. Z. 289, 320; $290,360$.

Emerson, R. \& Fox, D. L. (1940). Proc. Roy. Soc. B, 128, 275.

Haas, P. \& Hill, T. G. (1933). Ann. Bot., Lond., 47, 55.

Heilbron, I. M. (1942). J. chem. Soc. p. 79.
Heilbron, I. M., Parry, E. G. \& Phipers, R. F. (1935). Biochem. J. 29, 1376.

Heilbron, I. M. \& Phipers, R. F.(1935). Biochem. J.29, 1369.

Kuhn, R., Moewus, F. \& Jerchel, D. (1938). Ber. dtsch. chem. Ges. 71, 1541.

Kuhn, R., Moewus, F. \& Wendt, G. (1939). Ber. dtsch. chem. Ges. 72, 1702.

Moewus, F. (1938). Jb. wiss. Bot. 86, 753.

Murneek, A. E. (1934). Science, 79, 528.

Strain, H. H. (1934). J. biol. Chem. 105, 523.

Zechmeister, L. (1944). Chem. Rev. 34, 267. 